\title{
CAN LEVELS OF URINARY MATRIX METALLOPROTEINASES (MMPS) ACT AS AN ALTERNATIVE TO GLEASON'S SCORING IN PROSTATIC MALIGNANCIES
}

\author{
Sudipta Banerjee", Ranjan K. Dey², Jayanta K. Rout ${ }^{3}$, Amrita Mukherjee $^{4}$, Srabani Biswas ${ }^{5}$, Rupesh Gupta ${ }^{6}$ \\ ${ }^{1}$ Scholar, Department of Biochemistry, RG Kar Medical College, Kolkata, West Bengal. \\ ${ }^{2}$ Associate Professor, Department of Urology, RG Kar Medical College, Kolkata, West Bengal. \\ ${ }^{3}$ Assistant Professor, Department of Biochemistry, RG Kar Medical College, Kolkata, West Bengal. \\ ${ }^{4}$ Assistant Professor, Department of Biochemistry, RG Kar Medical College, Kolkata, West Bengal. \\ 5 Professor, Department of Biochemistry, RG Kar Medical College, Kolkata, West Bengal. \\ ${ }^{6}$ Scholar, Department of Urology, RG Kar Medical College, Kolkata, West Bengal.
}

\section{ABSTRACT}

\section{BACKGROUND}

Gleason's grading is an important prognostic parameter for prostatic malignancies. The invasiveness of the procedure coupled with seeding along the biopsy tract has prompted us to explore the scope of a noninvasive procedure in the form of assay of urinary matrix metalloproteinases (MMPs) with their inhibitors.

\section{MATERIALS AND METHODS}

Early morning midstream urine samples from 40 subjects including 28 cases suffering from carcinoma prostate and 12 subjects of prostatic benign conditions as controls were included in this study. ELISA was performed for each of the parameters. Nonparametric tests were employed for statistical evaluation at 95\% confidence interval $(\mathrm{p}<0.05)$.

\section{RESULTS}

The mean ranks of MMP7 and MMP13 of case group and control group are 23.55, 13.38 vs. 25.71, 8.33 respectively and MannWhitney $U$ values are 82.50 and 22.0 between case and control groups $(\mathrm{p}<0.01$ and $\mathrm{p}<0.001)$. We did not find any unanimous result in case of different tissue inhibitors (TIMP1 and TIMP2) of MMPs. Significant Spearman's correlation of Gleason's score with MMP-7 $(\rho=0.573, p=0.001)$ and MMP-13 $(\rho=0.402, p=0.034)$ in urine was found. However, no significant correlation has been found between free PSA, TIMP-1 and TIMP-2 with Gleason's score. Using Kruskal Wallis Test, we did not find any significant mean difference in rank of parameters with different Gleason's score excepting MMP7 ( $\chi^{2}=9.259, \mathrm{DF}=3$ and $\left.\mathrm{p}=0.026\right)$.

\section{CONCLUSION}

Our study suggesting that MMP7 and MMP13 in urine can be considered as an important substance for diagnosing prostate carcinoma as their levels were found to be higher in malignant than in benign cases.

\section{KEYWORDS}

Gleason Score; Metalloproteinases; Prostate Cancer; Prostate-Specific Antigen; Tissue Inhibitor of Metalloproteinases.

HOW TO CITE THIS ARTICLE: Banerjee S, Dey RK, Rout JK, et al. Can levels of urinary matrix metalloproteinases (MMPs) act as an alternative to Gleason's scoring in prostatic malignancies. J. Evolution Med. Dent. Sci. 2017;6(16):1281-1285, DOI: $10.14260 /$ Jemds/2017/278

\section{BACKGROUND}

Carcinoma prostate has been found to be the fourth most common malignant neoplasm among worldwide male population $^{(1)}$ and the incidence of this carcinoma is up to 20 fold higher in industrialised countries than developing countries.(2,3) An increased understanding of the biology of prostate carcinoma has led to the need for perception of mechanism of proper diagnosis.(4) Biopsy of prostatic tissue is the mainstay of diagnosis and assessment of severity. Gleason's scoring based on biopsy findings is used to grade the severity. Although it is a gold standard for diagnosis it is a

Financial or Other, Competing Interest: None.

Submission 12-01-2017, Peer Review 10-02-2017,

Acceptance 16-02-2017, Published 23-02-2017.

Corresponding Author:

Dr. Rupesh Gupta,

Department of Urology,

RG Kar Medical College

Khudiram Bose Sarani

Kolkata-700004,

West Bengal, India.

E-mail: drrupesgupta@gmail.com

DOI: $10.14260 /$ jemds $/ 2017 / 278$

(c) $(1)$ highly invasive process, hence the search for assay of a noninvasive procedure has prompted us to undertake this study.

The Gleason's grading system, the most commonly used classification scheme for the histological grading of prostate cancer is based on a low magnification microscopic description of the architecture of the cancer. The predominant pattern is given a grade between 1 and 5 which is then added to the second most dominant pattern. Thus, Gleason's score can be as low as 2 and as high as 10.(5,6) Our present study also aims at finding out if there is any significant correlation between different parameters and Gleason's score.

The matrix metalloproteinase (MMP) family is comprised of critically important extracellular proteases whose activity has been implicated in normal and pathological processes. The MMPs have a potential role in basal membrane and extracellular matrix degradation constantly facilitating tumour invasion and metastasis development. Endogenous tissue inhibitors of matrix metalloproteinase (TIMPs), typically hold MMPs in check, but in cancer the balance tumbles in favour of MMPs, which ultimately spill over from blood to urine.(7) 
Matrix metalloproteinase7 (MMP-7) one of the extracellular matrix dependent metalloproteinases, plays an important role in tissue invasion and metastasis.(8) There is significant correlation between levels of MMP-7 mRNA or the ratio of MMP7 mRNA/TIMP-1 mRNA and pathological stage, lymph node metastasis, vascular invasion and histological differentiation. The ratio is significantly increased in prostatic carcinoma patients with high level of PSA.(9) Bonaldi and Morgia et al have also cited increased serum level of MMP13 in prostatic carcinoma patients in different studies. The plasma concentration of MMP13 can have a diagnostic role in a prostatic carcinoma patient. $(10,11)$

The expression of several MMPs and TIMPs in prostatic carcinoma like MMP 2, 7, 9, 13 and 4 and TIMP 1 and 2 have recently been reported $(7,12,13)$ and shows that overexpression of MMPs induces tumour growth. $(14,15)$

The proteins encoded by TIMP gene family are natural inhibitors of matrix metalloproteinases. In addition to its inhibitory role against MMPs, the encoded protein is able to promote cell proliferation and may also have an antiapoptotic function.

Although activation of MMPs requires participation of TIMPs, its main role lies in inhibition of MMPs, it being a bifunctional enzyme. The need for re-evaluation of TIMP as a novel biomarker has arisen as secreted pro-MMPs form a complex with TIMP.(12)

\section{MATERIALS AND METHODS}

\section{Study Design}

The present study is a hospital based observational case control study involving Department of Biochemistry and Urology.

\section{Study Population+ \\ Cases and Controls}

For our study we have selected a group of 40 patients attending Urology Department of our college and hospital for TRUS guided biopsy due to complaints of prostatism clinically and serum PSA level $>4 \mathrm{ng} / \mathrm{mL}$.

The study followed the guidelines of the Helsinki declaration of 2009 (16) and was approved by the Institutional Ethics Committee. Written consent was taken from every participant.

\section{Inclusion Criteria}

As described in the study population.

\section{Exclusion Criteria}

Patients having urinary tract infection on antibiotic therapy, other associated urological disease, and catheterization, surgery of bladder or prostate, history of any malignancy (renal cell carcinoma, melanoma, breast and colorectal carcinoma etc.) or metastatic disease receiving adjuvant chemotherapy were excluded from the study group.

\section{Collection and Storage of Sample}

Early morning urinary samples for fPSA, MMP7, MMP13, TIMP-1 and TIMP- 2 were collected from 40 such patients and stored at $-20^{\circ} \mathrm{C}$ till further estimation. Samples were thawed to room temperature before every assay and repeated thaw is avoided.

\section{Estimation of Test Parameters}

For estimating all the parameters, ELISA (Enzyme linked immunosorbent assay) was done with commercially available Accu Bind ELISA reagent kit for urinary free PSA (LOT EIA23KIA6H581) and Ray Biotech ELISA reagent kit for human MMP7 (Lot\#: 1219140222), MMP13 (Lot\#: 1219140175), TIMP1 (Lot\#: 1219140191) and TIMP2 (Lot\#: 1219140192). Standard curve was performed for each assay using norms provided by the manufacturers.

TRUS guided multicore prostatic biopsy using trans-rectal USG probe and biopsy gun was performed on the subjects before discharge and the biopsy reports were collected on follow up.

From the histopathological reports, the Gleason's score was obtained for the malignant patients.

\section{RESULTS}

Patients were classified into benign $(\mathrm{B}, \mathrm{N}=12)$ and malignant $(\mathrm{M}, \mathrm{N}=28)$ groups according to biopsy results and statistical calculations were performed. Significance was considered at $95 \%$ confidence interval $(\mathrm{p}<0.05)$ for all statistical tests.

Since our sample size was small, nonparametric tests were done and all data were presented by their mean ranks. Evaluation of the statistical significance between mean ranks of different parameters of two groups were performed using Mann-Whitney $U$ test. The mean ranks of fPSA of cases and controls in the present study are 16.05, 30.88. Mann-Whitney $\mathrm{U}$ value is 43.50 between case and control group, this value shows high statistical significance at $\mathrm{p}<0.001$ levels (Table: 1 ).

The mean ranks of MMP7 and MMP13 of case group and control group in the present study are 23.55, 13.38 and 25.71, 8.33 respectively. Mann-Whitney $U$ values for MMP7 and MMP13 are respectively 82.50 and 22.0 between case and control group, these values shows high statistical significance at 0.01 and $<0.001$ levels respectively (Table: 1 ).

The mean rank of urinary TIMP-1 value in our study was slightly higher in malignant cases (21.71) than in benign conditions (17.67). The Mann-Whitney $U$ value of TIMP-1 between cases and controls is 134.0 which are not significant statistically. On the other hand, the mean rank of urinary TIMP-2 concentration was higher (17.30) in benign conditions than in malignant cases (27.96) and the Mann-Whitney U value was $78.50(p=0.008)$ which is statistically significant.

Spearman's rho correlation was used to determine correlation of different parameters with Gleason's scoring. Our study showed significant Spearman's correlation of MMP7 $(\rho=0.573, p=0.001)$ and MMP13 $(\rho=0.402, p=0.034)$ in urine with Gleason's score (Table: 2). However, no significant correlation had been found between free PSA, TIMP-1 and TIMP-2 with Gleason's score (Table: 2 ).

Kruskal Wallis test was used to check if the differences of mean ranks of different parameters were varying significantly with difference in Gleason's score. We did not find any significant mean difference in ranks of parameters with different Gleason's score excepting MMP7 $\left(\chi^{2}=9.259, \mathrm{DF}=3\right.$ and $\mathrm{p}=0.026$ ) (Table: $3 \& 4$ ). 


\begin{tabular}{|c|c|c|c|c|c|}
\hline & fPSA & MMP7 & MMP13 & TIMP1 & TIMP2 \\
\hline \multirow{2}{*}{ Mean Ranks } & Case:16.05 & Case:23.55 & Case:25.71 & Case:21.71 & Case: 17.30 \\
\cline { 2 - 6 } & Control:30.88 & Control:13.38 & Control:8.33 & Control:17.67 & Control:27.96 \\
\hline Mann-Whitney U & 43.50 & 82.50 & 22.0 & 134.0 & 78.50 \\
\hline $\begin{array}{c}\text { Significance } \\
\text { (p value) }\end{array}$ & $<0.001$ & 0.010 & $<0.001$ & 0.328 & 0.007 \\
\hline \multicolumn{7}{|r}{ Table 1. Showing Mean ranks of different Biochemical Parameters in Case and Control groups } \\
with Mann-Whitney U test and Statistical Significance between groups.
\end{tabular}

\begin{tabular}{|c|c|c|c|c|c|c|c|}
\hline & & & uPSA & MMP7 & MMP13 & TIMP1 & TIMP2 \\
\hline \multirow{3}{*}{ Spearman's rho } & \multirow{3}{*}{ Gleason's Scoring } & Correlation Coefficient & $(-) 0.078$ & $0.573^{* *}$ & $0.402^{*}$ & $(-) 0.115$ & 0.011 \\
\hline & & Significance ( $p$ value) & 0.692 & 0.001 & 0.034 & 0.560 & 0.957 \\
\hline & & $\mathrm{N}$ & 28 & 28 & 28 & 28 & 28 \\
\hline
\end{tabular}

\begin{tabular}{|c|c|c|c|c|c|}
\hline & \multicolumn{5}{|c|}{ Mean Ranks } \\
\hline $\begin{array}{c}\text { Gleason's } \\
\text { Scoring }\end{array}$ & UPSA & MMP 7 & MMP 13 & TIMP 1 & TIMP 2 \\
\hline $6.00(\mathrm{~N}=08)$ & 16.00 & 8.44 & 10.31 & 15.44 & 13.38 \\
\hline $7.00(\mathrm{~N}=14)$ & 14.11 & 15.07 & 14.75 & 14.54 & 15.71 \\
\hline $8.00(\mathrm{~N}=04)$ & 8.00 & 19.13 & 18.75 & 15.75 & 13.25 \\
\hline $9.00(\mathrm{~N}=02)$ & 24.25 & 25.50 & 21.00 & 8.00 & 13.00 \\
\hline $\begin{array}{c}\text { Table 3. Showing Mean ranks of different Biochemical } \\
\text { Parameters with respect to different Gleason's Scoring }\end{array}$ \\
\hline
\end{tabular}

\begin{tabular}{|c|c|c|c|c|c|}
\hline \multicolumn{7}{|c|}{ Test Statistics } \\
\hline & uPSA & MMP7 & MMP13 & TIMP1 & TIMP2 \\
\hline Chi-Square & 5.607 & 9.259 & 4.405 & 1.446 & 0.614 \\
\hline DF & 3 & 3 & 3 & 3 & 3 \\
\hline $\begin{array}{c}\text { Significance } \\
\text { (p value) }\end{array}$ & 0.132 & 0.026 & 0.221 & 0.695 & 0.893 \\
\hline
\end{tabular}

Table 4. Showing Chi-Square values and their Significance among different stages of Gleason's Score

\section{DISCUSSION}

This study has been designed to find a non-invasive biomaterial for prostatic malignancies. For this, 40 subjects were selected on the basis of inclusion and exclusion criteria of the study.

The pioneer works of Graves and colleagues(17) demonstrated the presence of PSA in urine but its role in cancer detection and management is still under controversy. The fact that urine contains more PSA than serum is advantageous for its extraction.

One study has shown decrease in urinary total PSA level in prostate carcinoma patients than in benign conditions although the overall value of urinary total PSA has been found to be higher than total serum PSA(18) in normal patients in previous studies.

Theoretically urinary PSA level should provide useful information about probable physiology and pathology of prostate. In pathological conditions like chronic inflammation, neoplasia with stenosis, compression or neovascularisation, the polarity of the epithelial cells gets reversed thereby releasing more PSA across the basement membrane. This leads to increase in serum PSA.(19-24) However, concomitant decrease in urinary PSA level occurs that is its level decreases in cancerous conditions than in benign conditions (though the actual urinary level remains higher than serum PSA).This has been potentially explained by an altered drainage of prostate secretions in prostatic urethra which leads to decreased excretion of total PSA and thereby increase in serum total PSA. (25)

Our findings regarding levels of urinary fPSA in prostatic malignancies compared to benign states of prostate corroborates with Bolduc $S$ et al (2007). The difference in mean ranks of fPSA of cases (16.05) and controls (30.88) in the present study shows high statistical significance $(U=43.50$, $\mathrm{p}<0.001$ ) (Table: 1 ).

MMP expression in prostate cancer was first described in 1991 by in situ hybridisation methods.(26) Stromal cells (e.g., fibroblasts, monocytes and macrophages) can synthesise MMPs directly, or they may produce some factors that initiate MMP synthesis. It has also been shown that tumour cells induce MMP synthesis in stromal cells in a paracrine manner.(27) In accordance with Gong et al (2014), there is an imbalanced expression of MMPs and TIMPs in prostate cancer tissue, manifested as a general loss of TIMPs and an upregulation of MMPs.(28) Gerhards et al (2001) suggested the elevation of MMPs in urine in hypersecretory states like high grade bladder neoplasia. (29)

Our study also corroborates that MMP synthesis and thereby excretion is increased in prostatic malignancies compared to benign states of prostate. The difference in mean ranks of MMP 7 (23.55 vs 13.38) and MMP 13 (25.71 vs 8.33) of case group and control group in the present study shows high statistical significance $(U=82.5, p=0.01 \& U=22.0, p<0.001$ levels respectively (Table: 1 ).

Several studies have demonstrated that elevated TIMP-1 level in tumour tissue or peripheral blood is associated with poor clinical outcomes in a range of malignancies.(30-36) However, in some other studies, TIMP-1 expression is low in the tumour tissue of prostate adenocarcinoma and many other solid tumours.(37) Thus, the role of TIMP cannot be clearly defined so far.

Similarly, TIMP-2 expression was found to be associated with shorter survival and higher rate of recurrence in prostate carcinoma.(38) Another group showed that high TIMP-2 expression in stromal cells was related to longer disease free survival when compared to a group with weak TIMP-2 staining.(39)

The mean rank of urinary TIMP-1 value in our study was slightly higher in malignant conditions (21.71 vs 17.67 ). 
The Mann-Whitney U value of TIMP-1 between cases and controls is 134.0 which are not significant statistically ( $p>0.05$ ) possibly due to lower sample size (Table: 1 ). On the other hand the mean rank of urinary TIMP-2 concentration was higher in benign conditions and the Mann-Whitney $\mathrm{U}$ value was $78.50(p=0.008)$ which is statistically significant. From the above results so obtained, urinary TIMPs cannot be suggested as important parameters for diagnosis of prostate cancer which corroborates previous studies (Table: 1 ).

One study conducted by Isisag et al in 2003 showed no correlation between expression of MMP9 and TIMP-1 and Gleason's score in 43 prostate cancer patients.(40) But our study showed significant Spearman's correlation of MMP7 ( $\rho=0.573, p=0.001)$ and MMP13 $(\rho=0.402, p=0.034)$ in urine with Gleason's score (Table: 2). However, no significant correlation had been found between free PSA, TIMP-1 and TIMP-2 with Gleason's score (Table: 2). No previous study in urine has been found on these parameters in subjects suffering from prostatic carcinoma. Using Kruskal Wallis Test, we did not find any significant mean difference in ranks of parameters with different Gleason's score excepting MMP7 $\left(\chi^{2}=9.259\right.$, $\mathrm{DF}=3$ and $\mathrm{p}=0.026$ ) (Table: $3 \& 4$ ).

\section{CONCLUSION}

Therefore, we can conclude that MMP7 and MMP13 in urine can be considered as important substance for diagnosing prostate carcinoma as their levels were found to be higher in malignant than in benign cases. Urinary free PSA, however, showed an inverse relationship with malignant cases while the tissue inhibitors of metalloproteinases, TIMP-1 and TIMP-2 had failed to show any significant change in prostate carcinoma. Further, when different parameters in malignant cases were correlated with Gleason's score, MMP7 emerged as the most significant noninvasive parameter to predict the severity of prostate carcinoma. However, no firm conclusion can be drawn due to lack of adequate number of samples possibly due to time constraint and further studies are needed to corroborate our results.

\section{REFERENCES}

[1] Ferlay J, Soerjomataram I, Dikshit R, et al. Cancer incidence and mortality worldwide: sources, methods and major patterns in GLOBOCAN 2012. Int J Cancer 2015;136(5):E359-86.

[2] Center MM, Jemal A, Lortet-Tieulent J, et al. International variation in prostate cancer incidence and mortality rates. Eur Urol 2012;61(6):1079-92.

[3] Kuruma H, Egawa S. Words of wisdom: re: international variation in prostate cancer incidence and mortality rates. Eur Urol 2013;63(3):583-4.

[4] Morris MJ, Scher HI. Novel strategies and therapeutics for the treatment of prostate carcinoma. Cancer 2000;89(6):1329-48.

[5] Partin AW, Steinberg GD, Pitcock RV, et al. Use of nuclear morphometry, Gleason histologic scoring, clinical stage, and age to predict disease-free survival among patients with prostate cancer. Cancer 1992;70(1):161-8.

[6] Epstein JI, Zelefsky MJ, Sjoberg DD, et al. A contemporary prostate cancer grading system: a validated alternative to the Gleason score. Eur Urol 2016;69(3):428-35.
[7] Di Carlo A, Mariano A, Terracciano D, et al. Matrix metalloproteinase- 2 and -9 in the urine of prostate cancer patients. Oncol Rep 2010;24(1):3-8.

[8] Szarvas T, Becker M, Dorp VF, et al. Elevated serum matrix metalloproteinase 7 levels predict poor prognosis after radical prostatectomy. Int J Cancer 2011;128(6):1486-92.

[9] Hashimoto K, Kihira Y, Matuo Y, et al. Expression of matrix metalloproteinase-7 and tissue inhibitor of metalloproteinase-1 in human prostate. J Urol 1998;160(5):1872-6.

[10] Bonaldi CM, Azzalis LA, Junqueira VB, et al. Plasma levels of E-cadherin and MMP-13 in prostate cancer patients: correlation with PSA, testosterone and pathological parameters. Tumori 2015;101(2):185-8.

[11] Morgia G, Falsaperla M, Malaponte G, et al. Matrix metalloproteinases as diagnostic (MMP-13) and prognostic (MMP-2, MMP-9) markers of prostate cancer. Urol Res 2005;33(1):44-50.

[12] Brehmer B, Biesterfeld S, Jakse G. Expression of matrix metalloproteinases (MMP-2 and -9) and their inhibitors (TIMP-1 and -2) in prostate cancer tissue. Prostate Cancer Prostatic Dis 2003;6(3):217-22.

[13] Zhong WD, Han ZD, He HC, et al. CD147, MMP-1, MMP2 and MMP-9 protein expression as significant prognostic factors in human prostate cancer. Oncology 2008;75(3-4):230-6.

[14] Bonfil RD, Dong Z, Filho TJC, et al. Prostate cancerassociated membrane type 1-matrix metalloproteinase: a pivotal role in bone response and intraosseous tumor growth. Am J Pathol 2007;170(6):2100-11.

[15] Roy R, Louis G, Loughlin KR, et al. Tumor-specific urinary matrix metalloproteinase fingerprinting: identification of high molecular weight urinary matrix metalloproteinase species. Clin Cancer Res 2008;14(20):6610-7.

[16] World Medical Association Inc. Declaration of Helsinki. Ethical principles for medical research involving human subjects. J Indian Med Assoc 2009;107(6):4035.

[17] Graves HC, Sensabaugh GF, Blake ET. Postcoital detection of a male-specific semen protein. Application to the investigation of rape. $\mathrm{N}$ Engl J Med 1985;312(6):338-43.

[18] Nilsson O, Peter A, Andersson I, et al. Antigenic determinants of prostate-specific antigen (PSA) and development of assays specific for different forms of PSA. Br J Cancer 1997;75(6):789-97.

[19] Lizana J, Moberg PJ, Eneroth P. Beta2-microglobulin, carcinoembryonic antigen and prostatic acid phosphatase in split ejaculates and urine voided before and after massage of the prostate. Arch Androl 1983;11(3):225-32.

[20] DeVere WRW, Meyers FJ, Soares SE, et al. Urinary prostate specific antigen levels: role in monitoring the response of prostate cancer to therapy. J Urol 1992;147(3 Pt 2):947-51.

[21] Breul J, Pickl U, Hartung R. Prostate-specific antigen in urine. Eur Urol 1994;26(1):18-21. 
[22] Uchijima Y, Yoshida K, Saitoh H. Significance of prostatic acid phosphatase, gamma-seminoprotein and prostatic specific antigen in the urine. First report: the measurement of PAP, gamma-Sm and PA in the urine of patients with prostatic diseases. Hinyokika Kiyo 1991;37(10):1255-60.

[23] Hillenbrand M, Bastian M, Steiner M, et al. Serum-tourinary prostate-specific antigen ratio in patients with benign prostatic hyperplasia and prostate cancer. Anticancer Res 2000;20(6D):4995-6.

[24] Pejcic T, Hadzi-Djokic J, Acimovic M, et al. Urinary prostate specific antigen: is the clinical use likely? Acta Chir Iugosl 2005;52(4):69-74.

[25] Bolduc S, Lacombe L, Naud A, et al. Urinary PSA: a potential useful marker when serum PSA is between $2.5 \mathrm{ng} / \mathrm{mL}$ and $10 \mathrm{ng} / \mathrm{mL}$. Can Urol Assoc J 2007;1(4):377-81.

[26] Pajouh MS, Nagle RB, Breathnach R, et al. Expression of metalloproteinase genes in human prostate cancer. J Cancer Res Clin Oncol 1991;117(2):144-50.

[27] Seitz C, Djavan B. Biological markers of prostate cancer. Ann Urol (Paris) 2006;40(6):329-35.

[28] Gong Y, Chippada-Venkata UD, Oh WK. Roles of matrix metalloproteinases and their natural inhibitors in prostate cancer progression. Cancers (Basel) 2014;6(3):1298-327.

[29] Gerhards S, Jung K, Koenig F, et al. Excretion of matrix metalloproteinases 2 and 9 in urine is associated with a high stage and grade of bladder carcinoma. Urology 2001;57(4):675-9.

[30] Nakopoulou L, Giannopoulou I, Stefanaki K, et al. Enhanced mRNA expression of tissue inhibitor of metalloproteinase-1 (TIMP-1) in breast carcinomas is correlated with adverse prognosis. J Pathol 2002;197(3):307-13.

[31] Aldulaymi B, Bystrom P, Berglund A, et al. High plasma TIMP-1 and serum CEA levels during combination chemotherapy for metastatic colorectal cancer are significantly associated with poor outcome. Oncology 2010;79(1-2):144-9.
[32] Crocker M, Ashley S, Giddings I, et al. Serum angiogenic profile of patients with glioblastoma identifies distinct tumor subtypes and shows that TIMP- 1 is a prognostic factor. Neuro Oncol 2011;13(1):99-108.

[33] Guedez L, Stetler-Stevenson WG. The prognostic value of TIMP-1 in multiple myeloma. Leuk Res 2010;34(5):576-7.

[34] Yoshikawa T, Cho H, Tsuburaya A, et al. Impact of plasma tissue inhibitor of metalloproteinase-1 on longterm survival in patients with gastric cancer. Gastric Cancer 2009;12(1):31-6.

[35] Yoshino Y, Kageshita T, Nakajima M, et al. Clinical relevance of serum levels of matrix metallopeptidase-2, and tissue inhibitor of metalloproteinase- 1 and -2 in patients with malignant melanoma. J Dermatol 2008;35(4):206-14.

[36] Yukawa N, Yoshikawa T, Akaike M, et al. Impact of plasma tissue inhibitor of matrix metalloproteinase-1 on long-term survival in patients with colorectal cancer. Oncology 2007;72(3-4):205-8.

[37] Lokeshwar BL, Selzer MG, Block NL, et al. Secretion of matrix metalloproteinases and their inhibitors (tissue inhibitor of metalloproteinases) by human prostate in explant cultures: reduced tissue inhibitor of metalloproteinase secretion by malignant tissues. Cancer Res 1993;53(19):4493-8.

[38] Ross JS, Kaur P, Sheehan CE, et al. Prognostic significance of matrix metalloproteinase 2 and tissue inhibitor of metalloproteinase 2 expression in prostate cancer. Mod Pathol 2003;16(3):198-205.

[39] Trudel D, Fradet Y, Meyer F, et al. Membrane-type-1 matrix metalloproteinase, matrix metalloproteinase 2 , and tissue inhibitor of matrix proteinase 2 in prostate cancer: identification of patients with poor prognosis by immunohistochemistry. Hum Pathol 2008;39(5):731-9.

[40] Isisag A, Nese $\mathrm{N}$, Ermete $\mathrm{M}$, et al. Col IV and Fn distribution in prostatic adenocarcinoma and correlation of 67LR, MMP-9 and TIMP-1 expression with Gleason score. Anal Quant Cytol Histol 2003;25(5):263-72. 